Marquette University

e-Publications@Marquette

$10-2016$

\title{
Factor Analysis of the Milwaukee Inventory for Subtypes of Trichotillomania-Adult Version
}

Jennifer R. Alexander

Texas A \& M University - College Station

David C. Houghton

Texas A\&M University - College Station

Michael P. Twohig

Utah State University

Martin E. Franklin

University of Pennsylvania

Stephen M. Saunders

Marquette University, stephen.saunders@marquette.edu

See next page for additional authors

Follow this and additional works at: https://epublications.marquette.edu/psych_fac

Part of the Psychology Commons

\section{Recommended Citation}

Alexander, Jennifer R.; Houghton, David C.; Twohig, Michael P.; Franklin, Martin E.; Saunders, Stephen M.; Neal-Barnett, Angela M.; Compton, Scott N.; and Woods, Douglas W., "Factor Analysis of the Milwaukee Inventory for Subtypes of Trichotillomania-Adult Version" (2016). Psychology Faculty Research and Publications. 229.

https://epublications.marquette.edu/psych_fac/229 


\section{Authors}

Jennifer R. Alexander, David C. Houghton, Michael P. Twohig, Martin E. Franklin, Stephen M. Saunders, Angela M. Neal-Barnett, Scott N. Compton, and Douglas W. Woods 
Marquette University

e-Publications@Marquette

\section{Psychology Faculty Research and Publications/College of Arts and Sciences}

This paper is NOT THE PUBLISHED VERSION; but the author's final, peer-reviewed manuscript. The published version may be accessed by following the link in th citation below.

Journal of Obsessive Compulsive and Related Disorders, Vol. 11 (October 2016): 31-38. DOI. This article is (C Elsevier and permission has been granted for this version to appear in e-Publications@Marquette. Elsevier does not grant permission for this article to be further copied/distributed or hosted elsewhere without the express permission from Elsevier.

\section{Factor Analysis of the Milwaukee Inventory for Subtypes of Trichotillomania-Adult Version}

Jennifer R. Alexander

Department of Psychology, Texas A\&M University, College Station, TX

David C. Houghton

Department of Psychology, Texas A\&M University, College Station, TX

Michael P. Twohig

Department of Psychology, Utah State University, Logan, UT

Martin E. Franklin

Department of Psychiatry, University of Pennsylvania School of Medicine, Philadelphia, PA

Stephen M. Saunders

Department of Psychology, Marquette University, Milwaukee, WI

Angela M. Neal-Barnett

Department of Psychology, Kent State University, Kent, $\mathrm{OH}$

Scott N. Compton

Department of Psychiatry and Behavioral Sciences, Duke University School of Medicine, Durham, NC

Douglas W. Woods

Department of Psychology, Marquette University, Milwaukee, WI 


\section{Abstract}

The Milwaukee Inventory for Subtypes of Trichotillomania-Adult Version (MIST-A; Flessner et al., 2008) measures the degree to which hair pulling in Trichotillomania (TTM) can be described as "automatic" (i.e., done without awareness and unrelated to affective states) and/or "focused" (i.e., done with awareness and to regulate affective states). Despite preliminary evidence in support of the psychometric properties of the MIST-A, emerging research suggests the original factor structure may not optimally capture TTM phenomenology. Using data from a treatment-seeking TTM sample, the current study examined the factor structure of the MIST-A via exploratory factor analysis. The resulting two factor solution suggested the MIST-A consists of a 5-item "awareness of pulling" factor that measures the degree to which pulling is done with awareness and an 8-item "internal-regulated pulling" factor that measures the degree to which pulling is done to regulate internal stimuli (e.g., emotions, cognitions, and urges). Correlational analyses provided preliminary evidence for the validity of these derived factors. Findings from this study challenge the notions of "automatic" and "focused" pulling styles and suggest that researchers should continue to explore TTM subtypes.

\section{Introduction}

The development and refinement of psychometrically validated rating scales are vital practices in the pursuit of evidence-based assessment. The Milwaukee Inventory for Subtypes of TrichotillomaniaAdult Version (MIST-A) is the only psychometrically validated instrument that assesses pulling styles in adults with Trichotillomania (TTM; also referred to as Hair Pulling Disorder; Flessner et al., 2008), a disorder characterized by repetitive hair pulling that causes hair loss or thinning and persists despite repeated attempts to stop (American Psychiatric Association [APA], 2013). Based on common conceptualizations of TTM pulling styles, the MIST-A assesses two styles: "focused" (i.e., pulling that is done with awareness and to regulate cognitive/affective states) and "automatic" (i.e., pulling that is performed outside of awareness and that is unrelated to cognitive/affective states; Begotka, Woods, \& Wetterneck, 2004; Duke, Keeley, Geffken et al., 2010; Flessner et al., 2008; Woods et al., 2006). However, recent advances in the understanding of hair pulling variability indicate that the MIST-A factor structure, as well as the focused/automatic conceptualization on which the MIST-A is based, may not accurately describe hair pulling in TTM (e.g., Diefenbach, Mouton-Odum, \& Stanley, 2002; Duke, Keeley, \& Ricketts, 2010; Duke, Keeley, Geffken et al., 2010; Shusterman, Feld, Baer, \& Keuthen, 2009). As accurate identification and assessment of TTM pulling styles may lead to important conceptual and treatment advances (Flessner et al., 2008; Franklin, Zagrabbe, \& Benavides, 2012; Harrison \& Franklin, 2012), the factor structure of the MIST-A merits further consideration. 
Flessner et al. (2008) first examined the factor structure of an initial 24-item MIST-A using data collected from an internet survey completed by 1697 adults with self-reported TTM. Exploratory factor analysis of a subsample $(N=848)$ supported a 15 -item measure with a two-factor solution. Factor 1 , the "focused" pulling subscale, consisted of 10 items and accounted for $17.1 \%$ of the observed variance. Factor 2, the "automatic" pulling subscale, consisted of 5 items and accounted for $13 \%$ of the variance. Using the remaining survey respondents $(N=849)$, confirmatory factor analysis, internal consistency analysis, and convergent validity analyses further corroborated this two-factor solution. Despite the preliminary evidence in favor of the MIST-A factor structure, the study had several limitations as noted by Flessner et al. (2008). First, data were collected via an internet-based survey, calling into question the generalizability of the results to persons with confirmed TTM diagnoses. Moreover, the percentage of variance accounted for by the "focused" and "automatic" factors in the Flessner study (30.1\%) was relatively low (Henson \& Roberts, 2006), implying that additional factors may exist. In addition to these limitations, a recent attempt to replicate the factor structure of the MIST-A concluded that the MIST-A consisted of an "Intention" factor and an "Emotion" factor rather than an "automatic" factor and a "focused" factor (Keuthen et al., 2015). Such results suggest the MIST-A structure should be reexamined.

Advances in the conceptualization of TTM also call into question the utility of the MIST-A factor structure. Despite the putative dichotomy between "focused" and "automatic" pulling, most individuals with TTM report engaging in both styles (du Toit, van Kradenburg, Niehaus, \& Stein, 2001; Lochner, Seedat, \& Stein, 2010) and have difficulty ascertaining whether pulling in a given episode should be labeled as "focused" or "automatic" (Woods \& Twohig, 2008). Such findings suggest that the "focused" and "automatic" styles may be neither discrete nor exhaustive. One reason that the "focused"/ "automatic" dichotomy may not hold is the fact that the "automatic" and "focused" constructs conflate awareness of pulling with its capacity to regulate internal experiences. Indeed, research suggests that pulling done both with and without awareness varies in its ability to regulate internal states (Diefenbach et al., 2002; Duke, Keeley, Geffken et al., 2010; Duke, Keeley, Ricketts et al., 2010; Keuthen, Bohne, Himle, \& Woods, 2005; Panza, Pittenger, \& Bloch, 2013; Shusterman et al., $\underline{2009}$ ), suggesting that awareness and regulation capacity may actually be independent dimensional characteristics of hair pulling. As such, TTM pulling may be (a) done with awareness and to regulate internal states (consistent with the "focused" style), (b) done without awareness and unrelated to regulation of internal states (consistent with the "automatic" style), (c) done with awareness and unrelated to regulation of internal states, and (d) done without awareness and to regulate internal states. Unfortunately, however, the MIST-A's factor structure may not capture this possibility. 
In light of these observations and the importance of the accurate identification of TTM pulling styles for treatment development, we examined the factor structure of the MIST-A in a treatment-seeking TTM sample. We conducted an exploratory factor analysis on the MIST-A and examined the relationship between the derived MIST-A factors and validity indices (e.g., participant characteristics, anxiety, depression, and disorder severity).

\section{Method}

\subsection{Sample}

Participants were recruited as part of a randomized, controlled trial of psychotherapy for TTM.

Recruitment was accomplished via standard clinic referrals, advertisements in local physicians' offices, bus and radio advertisements, targeted mailing using Trichotillomania Learning Center (TLC) mailing lists, and advertisements on the TLC website (www.trich.org). Interested persons contacted a TTM specialty clinic and were phone screened before undergoing a more extensive in-person assessment.

Inclusion criteria included: (a) ages 18-65, (b) fluent in English, (c) $\geq 85$ on the Wechsler Test of Adult Reading (WTAR-IQ; The Psychological Corporation, 2001), (d) current DSM-IV TTM diagnosis, (e) $\geq 12$ on the Massachusetts General Hospital Hairpulling Scale (MGH-HS; Keuthen et al., 1995), and (f) ability to maintain outpatient status. Exclusion criteria included: (a) current DSM-IV diagnosis of bipolar

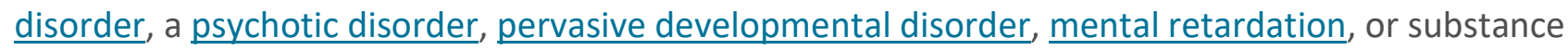
dependence (except for nicotine dependence), or (b) current suicide risk.

One-hundred seventeen individuals were screened for the clinical trial; 91 completed the baseline visit and participated in the current study. Eighty percent of the participants had at least one comorbid diagnosis. See Table 1 for additional participant demographic information.

Table 1. Participant demographics.

\begin{tabular}{cr} 
Variables & $\boldsymbol{n}(\%)$ \\
\hline Gender & \\
Female & $84(92.3 \%)$ \\
Male & $7(7.7 \%)$ \\
Race & \\
White & $76(83.5 \%)$ \\
Black & $11(12.1 \%)$ \\
Asian & $1(1.1 \%)$
\end{tabular}




\begin{tabular}{|c|c|}
\hline Variables & $n(\%)$ \\
\hline Other & $3(3.3 \%)$ \\
\hline \multicolumn{2}{|l|}{ Ethnicity } \\
\hline Non-Hispanic or Latino & 90 (98.9\%) \\
\hline Hispanic or Latino & $1(1.1 \%)$ \\
\hline \multicolumn{2}{|l|}{ Lifetime Comorbidity } \\
\hline Obsessive-Compulsive Disorder & $7(7.7 \%)$ \\
\hline Anxiety Disorder & $49(53.8 \%)$ \\
\hline Depressive Disorder & $28(30.8 \%)$ \\
\hline Bipolar Disorder & $1(1.1 \%)$ \\
\hline Eating Disorder & $5(5.5 \%)$ \\
\hline Substance Disorder & $22(24.2 \%)$ \\
\hline \multirow[t]{2}{*}{ Trauma/Adjustment Disorder } & $16(17.6 \%)$ \\
\hline & $M(S D)$ \\
\hline Age & $35.04(12.68)$ \\
\hline MGH-HS & $16.99(4.65)$ \\
\hline NIMH-TSS & $14.53(3.66)$ \\
\hline BAI & $12.60(10.75)$ \\
\hline BDI-II & $13.33(10.16)$ \\
\hline AAQ-TTM & $31.72(10.97)$ \\
\hline WTAR-IQ & $104.19(10.06)$ \\
\hline
\end{tabular}

Note. $\mathrm{MGH}-\mathrm{HS}=$ Massachusetts General Hospital Hairpulling Scale; NIMH-TSS = National Institute of Mental Health Trichotillomania Severity Scale; BAI = Beck Anxiety Inventory; BDI-II = Beck Depression Inventory-II; AAQ-TTM = Acceptance and Action Questionnaire-Trichotillomania; WTAR-IQ = Wechsler Test of Adult Reading.

Several researchers suggest that a participant to item ratio of at least 5:1 indicates the sample is adequate for factor analysis (Cattell, 1978; Gorsuch, 1974; Stevens, 1996). As the participant to item ratio in the current sample was 6:1, it was inferred that the sample would be sufficient for factor analysis.

\subsection{Measures}


The Milwaukee Inventory of Subtypes of Trichotillomania- Adult Version(MIST-A; Flessner et al., 2008) is a 15-item self-report measure that assesses the degree to which individuals engage in a "focused" and an "automatic" pulling style. "Focused" pulling is assessed on a 10-item subscale, and "automatic" pulling is assessed on a separate 5-item subscale. Items are scored on a 0 ("not true for any of my pulling") to 9 ("true for all of my hair pulling") Likert scale, resulting in total scores of 0-90 on the "focused" pulling subscale and total scores of 0-45 on the "automatic" pulling subscale. The MIST-A has demonstrated acceptable reliability and validity in a self-reported TTM sample (Flessner et al., 2008).

The Massachusetts General Hospital Hairpulling Scale (MGH-HS; Keuthen et al., 1995) is a seven-item self-report measure of TTM severity. Items assess the frequency, severity, and controllability of the pulling behavior and the urges to pull. In addition, one item assesses the distress consequent to the pulling behavior. Items are ranked on a 5-point Likert scale resulting in total scores that range from 0 to 28. Higher scores indicate greater TTM severity. Research has indicated that the MGH-HS demonstrates adequate reliability and validity in clinical TTM samples (Keuthen et al., 2007; O'Sullivan et al., 1995). In the current sample, the MGH-HS demonstrated acceptable internal consistency ( $\alpha$ $=.83)$.

The National Institute of Mental Health Trichotillomania Severity Scale (NIMH-TSS; Swedo, Rapoport, Leonard, Lenane, \& Cheslow, 1989) is a five-item, semi-structured interview that assesses TTM severity. Items pertain to time spent pulling, ability to resist pulling, and the distress and daily life interference that result from pulling. Items are scored on a 0-5 scale, resulting in total scores that range from 0 to 25. Higher scores indicate greater TTM severity. The NIMH-TSS has demonstrated adequate construct validity in TTM samples (Diefenbach, Tolin, Crocetto, Maltby, \& Hannan, 2005; Stanley, Breckenridge, Snyder, \& Novy, 1999; Swedo et al., 1989). However, as has been observed elsewhere (Diefenbach et al., 2005), the NIMH-TSS demonstrated moderate to weak internal consistency in the current sample ( $\alpha=.52)$.

The Beck Anxiety Inventory (BAl; Beck, Epstein, Brown, \& Steer, 1988) is a 21-item self-report measure of various anxiety symptoms. Items are rated on a scale of 0 ("not at all") to 3 ("severely- it bothered me a lot"), resulting in total scores that range from 0 to 63. Higher scores denote greater anxiety. The BAl has demonstrated high internal consistency and strong concurrent validity in clinical samples (Beck \& Steer, 1990; Beck et al., 1988; Fydrich, Dowdall, \& Chambless, 1992). In the current sample, the BAI demonstrated excellent internal consistency $(\alpha=.92)$. 
The Beck Depression Inventory-II (BDI-II; Beck, Steer, \& Brown, 1996) is a 21-item self-report measure of clinical depression. Items are rated on a 0-3 scale, resulting in total scores that range from 0 to 63. Higher scores denote greater depression. The BDI has demonstrated strong psychometric properties in clinical samples (Beck et al., 1996; Sprinkle et al., 2002). In the current sample, the BDI demonstrated excellent internal consistency $(\alpha=.92)$.

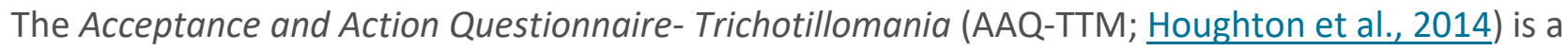
nine-item self-report measure of experiential avoidance (also referred to as psychological inflexibility) specific to TTM. Items are rated on a 1 ("never true") to 7 ("always true") scale. Total scores are calculated by summing item scores together, resulting in total scores ranging from 9 to 63 . Lower scores are indicative of greater TTM-specific experiential avoidance. The AAQ-TTM has demonstrated adequate reliability and validity in a TTM sample (Houghton et al., 2014). In the current sample, the AAQ-TTM demonstrated acceptable internal consistency $(\alpha=.84)$.

The Wechsler Test of Adult Reading (WTAR-IQ; The Psychological Corporation, 2001) is a word-reading task that estimates adult test takers' IQ. The WTAR has demonstrated high test-retest reliability and strong convergent validity (Strauss, Sherman, \& Spreen, 2006; The Psychological Corporation, 2001).

\subsection{Procedure}

Data were collected as part of a randomized, controlled trial conducted at the University of WisconsinMilwaukee. The trial is publicly listed on the National Institutes of Mental Health human subject trials registry (ClinicalTrials.gov; \#NCT00872742). The present study received IRB approval from University of Wisconsin-Milwaukee (IRB \#09-039) and Texas A\&M University (IRB2013-3025 M). The study was performed in compliance with the Code of Ethics of the World Medical Association (Declaration of Helsinki).

Individuals who met inclusion criteria were invited to the research facility, where consent for participation in the treatment study was obtained. As part of baseline assessment, participants completed all present study measures. Data for this study were taken from this baseline visit.

\section{Results}

\subsection{Exploratory factor analysis (EFA)}

Kaiser-Meyer-Olkin (KMO =.66) and Bartlett's Test of Sphericity $\left(\chi^{2}=582.47, p<.001\right)$ indicated the data

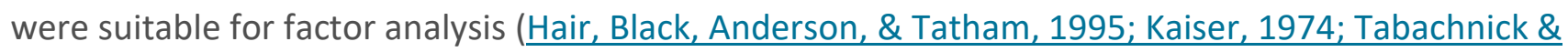


Fidell, 2007). The 15 items of the MIST-A were subjected to principal axis factor analysis in IBM SPSS Version 20. As suggested by Tabachnick and Fidell (2007), the data were first submitted to an oblique rotation (Promax, kappa 4) to examine whether an oblique or orthogonal rotation solution would be most appropriate for analysis. Two factors were extracted from this oblique rotation. However, as the resulting factor correlations were less than .32, it was inferred that an orthogonal rotation may be more appropriate (Tabachnick \& Fidell, 2007). Consequently, the data were submitted to an orthogonal rotation (varimax). Interpretation of the scree plot according to guidelines by $\underline{\text { Cattell and }}$ Vogelmann (1977) suggested a two-factor solution. The first factor, labeled the "internal-regulated pulling" subscale, had an eigenvalue of 3.68 and accounted for $24.55 \%$ of the variance. The second factor, labeled the "awareness of pulling" subscale, had an eigenvalue of 3.27 and accounted for $21.77 \%$ of the variance.

Items were interpreted to be representative of a factor if they had item-factor loadings of .40 or higher (Flessner et al., 2008; Hair et al., 1995; see Table 2for item-factor loading coefficients and communalities and see Table 3 for the current paper's MIST-A factor structure compared to the factor structure proposed by Flessner et al. (2008) and Keuthen et al. (2015)). Item-factor loadings suggested that the "internal-regulated pulling" subscale consisted of 8 items, while the "awareness of pulling" subscale consisted of 5 items. Neither item 3 ("I am in an almost 'trance-like' state when I pull my hair") nor item 6 ("I pull my hair while I am looking in the mirror") loaded onto a specific factor at .40 or higher, and both items were excluded from further analyses.

Table 2. Item-factor loadings resulting from varimax rotation.

\section{Items}

Factor 1

Loadings

Factor 2

Loadings

Communality

“Internal-Regulated Pulling" Subscale

4.

I have thoughts about wanting to pull my hair before I actually
pull

.46

$-.39$

.42

8.

I pull my hair when I am anxious or upset

.56

.398

.81

9.

I intentionally start pulling my hair

.48

$-.31$

.34

10.

I pull my hair when I am experiencing a negative emotion, such $\quad .58$

.34

.82

as stress, anger, frustration, or sadness

11.

I have a "strange" sensation just before I pull my hair

.51

$-.09$

.37 
13.

I pull my hair because of something that has happened to me $\quad .63$ during the day

14.

I pull my hair to get rid of an unpleasant urge, feeling, or thought

15.

I pull my hair to control how I feel

"Awareness of Pulling" Subscale

1.

I pull my hair when I am concentrating on another activity

2.

I pull my hair when I am thinking about something unrelated to $\quad .09$ hair pulling

5.

I use tweezers or some other device other than my fingers to pull my hair

7.

I am usually not aware of pulling my hair during a pulling $\quad-.05$ episode

12.

I don't notice that I have pulled my hair until after it's happened

Items Not Retained

3.

I am in an almost "trance-like" state when I pull my hair

6.

I pull my hair while I am looking in the mirror
.07

.44

.48

.29

.74

$<.01$

.68

.79

$-.04$

.73

.57

.54

$\begin{array}{ll}-.54 & .52\end{array}$

23

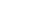

.05

.77

.12

.67

.56

.15

.36

.17

$-.39$

Note. Bolded item-factor loadings exceeded the cutoff (.40) for item inclusion.

Table 3. The MIST-A items grouped by the evaluations one by the current study, Flessner et al. (2008), and Keuthen et al. (2015).

Current factor structure

$\begin{array}{cc}\begin{array}{c}\text { Awareness } \\ \text { of Pulling }\end{array} & \text { Internal- } \\ & \text { Regulated Pulling }\end{array}$

4

1
Factor structure proposed by Flessner et al. (2008)
Factor structure proposed by Keuthen et al. (2015) factor structure

Focused Automatic Intention Emotion

4

1

1 
Current factor structure

Awareness
of Pulling

8

9

10

11

13

14

15
Factor structure proposed

by Flessner et al. (2008)
Factor structure proposed by Keuthen et al. (2015) factor structure

Focused Automatic

Intention

Emotion Regulated Pulling

2

3

7

12
10

11

13

14

15
2

$4(\mathrm{R})$

$5(\mathrm{R})$

$6(\mathrm{R})$

7

$9(\mathrm{R})$

12

Note. MIST-A = Milwaukee Inventory for Subtypes of Trichotillomania-Adult Version. (R) refers to reverse-scored items.

\subsection{Internal consistency}

Cronbach's alpha was used to measure the internal consistency of each derived subscale. Initial analyses suggested that the internal consistency of the "internal-regulated pulling" subscale $(\alpha=.80)$ and the "awareness of pulling" subscale ( $\alpha=.74)$ were adequate (Cortina, 1993; Kline, 2000).

\subsection{Resulting MIST-A subscales}

EFA and internal consistency analyses suggested an 8-item "internal-regulated pulling" subscale, resulting in total subscale scores that ranged from 0 to 72 . Likewise, these analyses suggested a 5-item "awareness of pulling" subscale, resulting in scores that ranged from 0 to 45 . Higher scores on the "internal-regulated pulling" subscale are indicative of pulling that serves a stronger internal-regulation function. In contrast, higher scores on the "awareness of pulling" subscale are indicative of pulling that is performed without awareness, and lower scores indicate greater awareness of pulling.

To determine whether the derived subscales were related, they were subjected to correlational analysis. As scores on the MIST-A "awareness of pulling" subscale were not normally distributed, a Spearman's rho correlation was calculated. This correlation showed that the two subscales were not 
significantly correlated $\left(r_{s}=.06, p=.60\right)$. As a result, these subscales were considered separately in subsequent analysis.

\subsection{Construct validity}

Correlational analyses were used to examine the validity of each derived subscale. Previous research suggests that the degree to which pulling functions to regulate internal experiences is positively related to negative affect (Duke, Keeley, Geffken et al., 2010; Duke, Keeley, \& Ricketts, 2010; Shusterman et al., 2009), experiential avoidance (i.e., the tendency to avoid unpleasant, internal experiences via maladaptive practices; Begotka et al., 2004; Houghton et al., 2014), and disorder severity (Begotka et al., 2004; Houghton et al., 2014; Norberg, Wetterneck, Woods, \& Conelea, 2007; Shusterman et al., 2009). Consequently, we hypothesized that the "internal-regulated pulling" subscale would be positively related to anxiety, depression, experiential avoidance, and TTM severity.

Similarly, previous research suggests that awareness of pulling may be positively related to intellectual maturity (Panza et al., 2013) and specific aspects of disorder severity, such as frequency of hair pulling (Begotka et al., 2004; Norberg et al., 2007). Accordingly, we hypothesized that the "awareness of pulling" subscale would be negatively associated with age, reading ability, and disorder severity as measured by the MGH-HS and NIMH-TSS (as lower scores on the "awareness of pulling" subscale indicate greater awareness of pulling).

To examine whether each subscale was sufficiently representative of its hypothesized construct, each of the derived subscales was correlated with anxiety (BAI), depression (BDI-II), experiential avoidance (AAQ-TTM), disorder severity (MGH-HS and NIMH-TSS), and participant characteristics (i.e., age and IQ [WTAR-IQ standard score]; see Table 4 for correlation coefficients). Spearman's rho coefficients were derived because scores on the MIST-A "awareness of pulling" subscale were not normally distributed. A Bonferroni correction for multiple correlations resulted in interpreting alpha at .003 or lower as being statistically significant.

Table 4. Spearman's rho correlations between the MIST-A awareness of pulling subscale, MIST-A emotion regulation subscale, and other variables of interest.

$\begin{array}{llllllllll}\text { Measures } & 1 & 2 & 3 & 4 & 5 & 6 & 7 & 8\end{array}$

1.

MIST-A Awareness of Pulling

2. $-.01-$ 
Measures

MIST-A Internal-Regulated Pulling

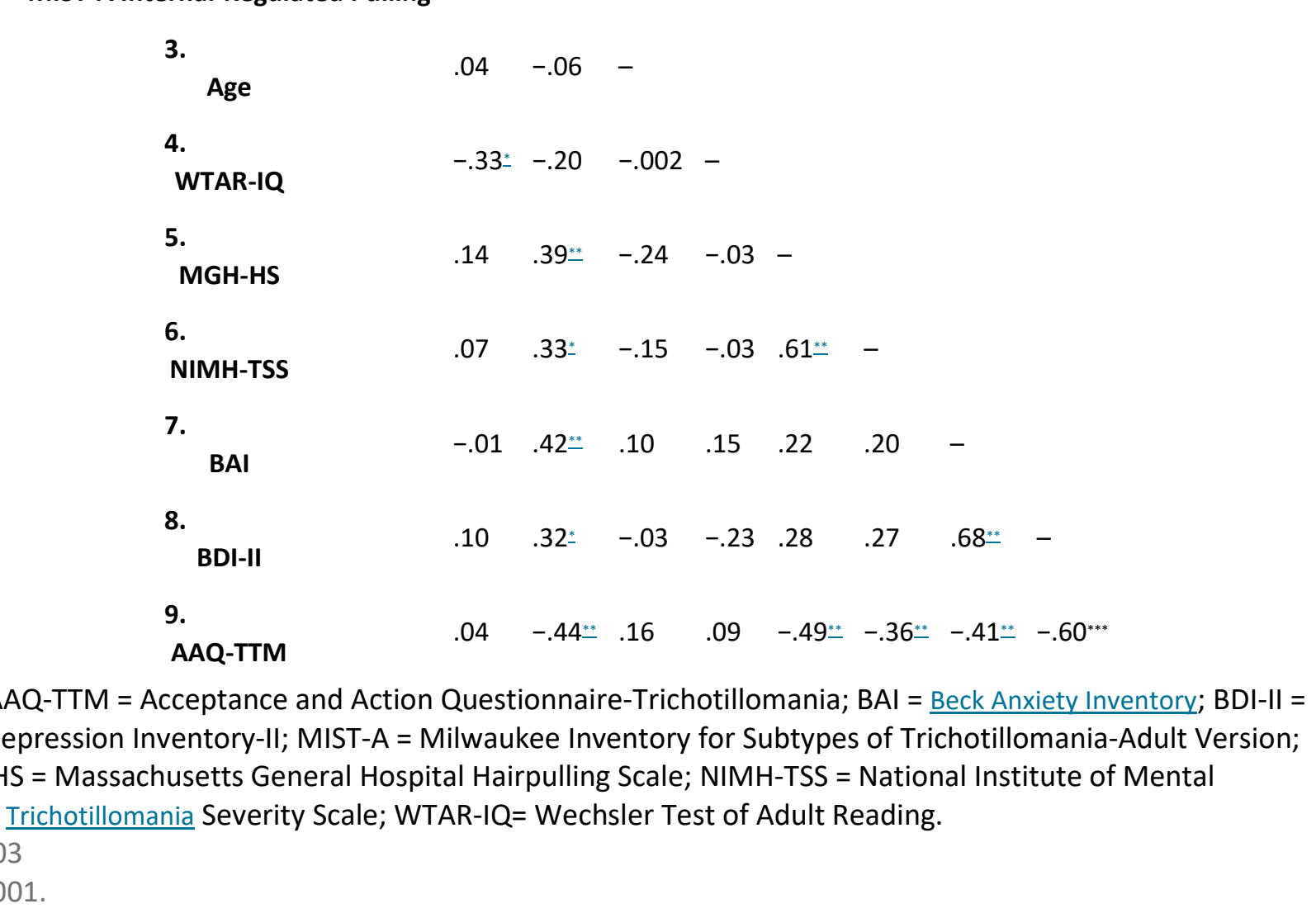

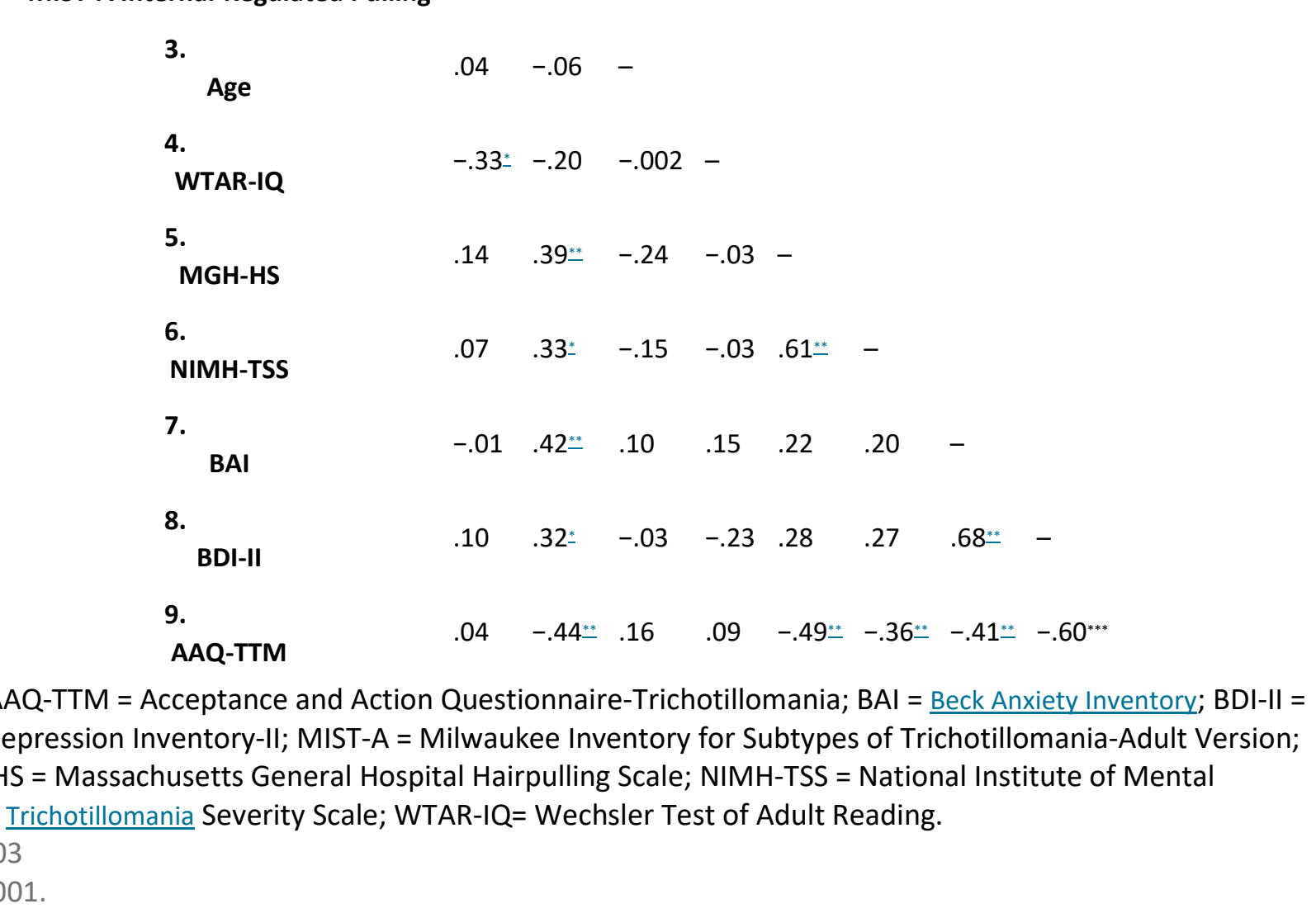

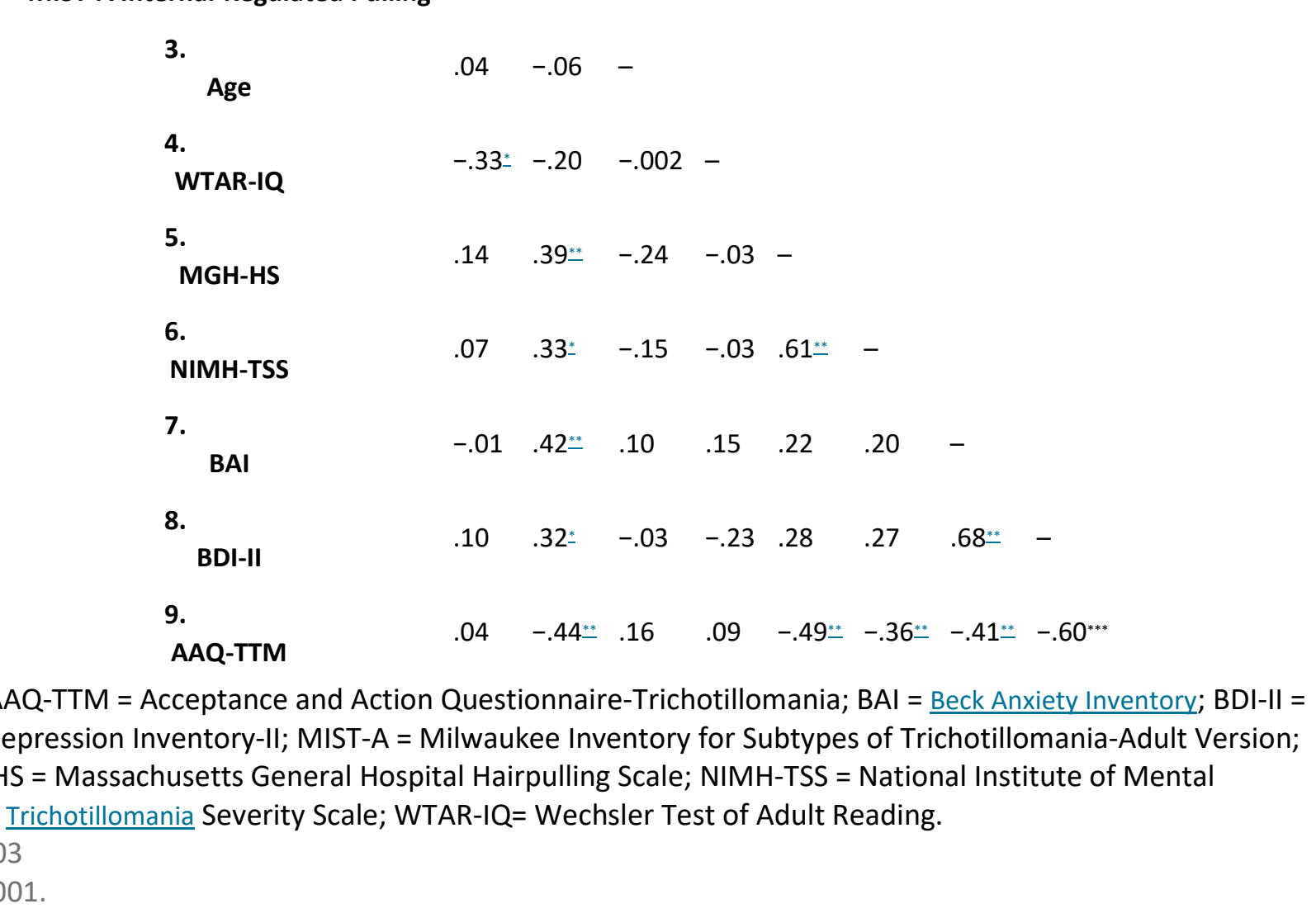

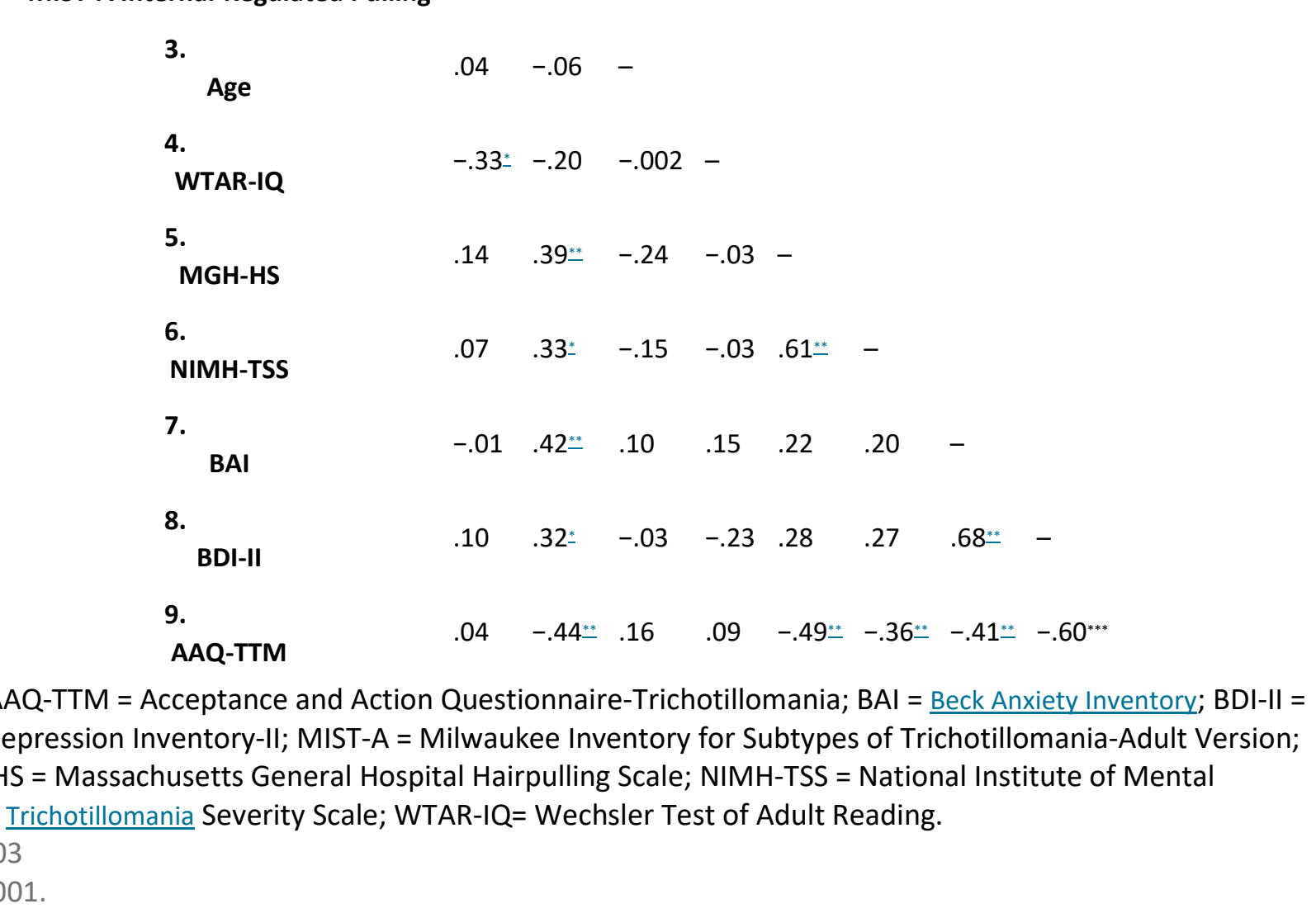

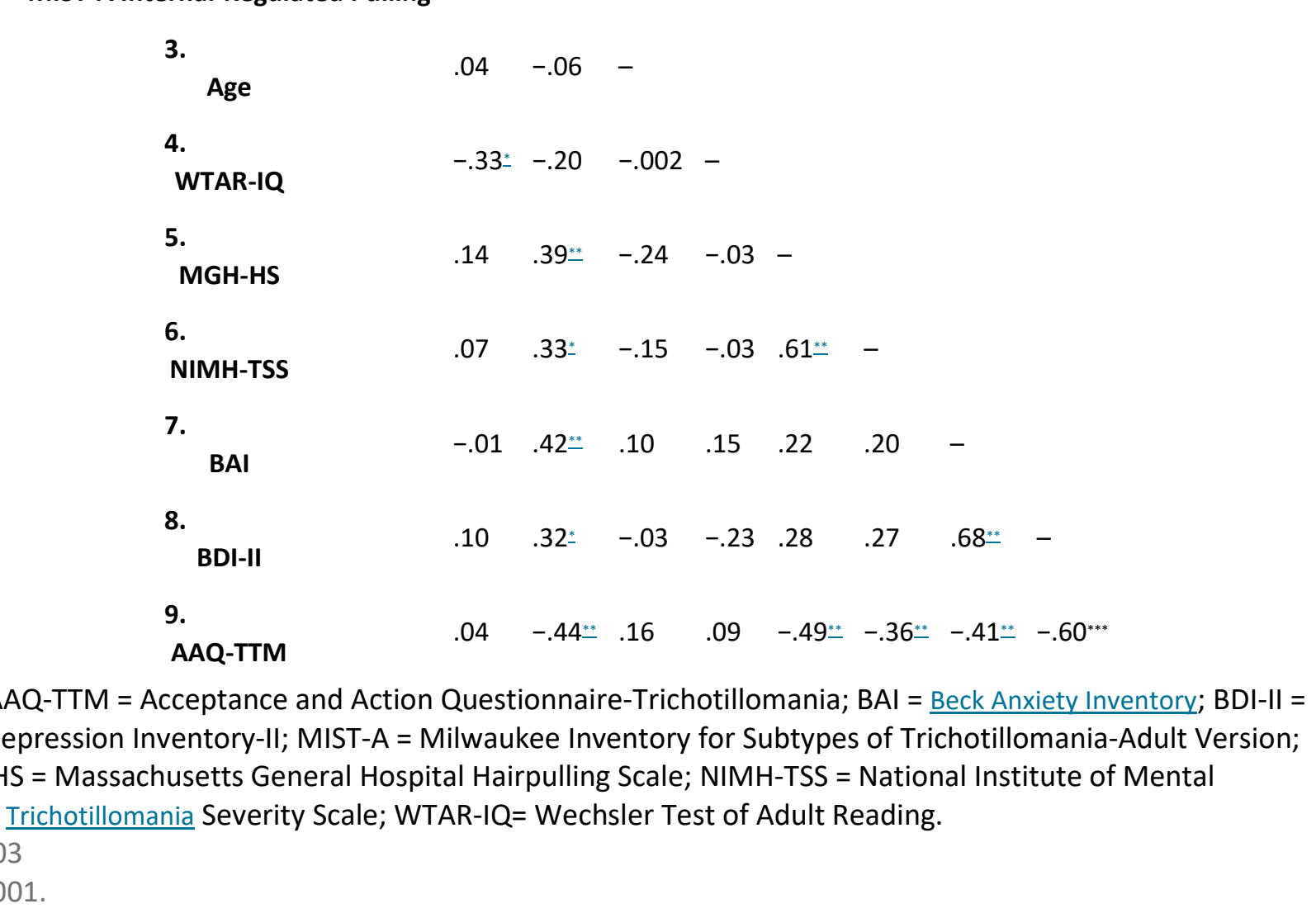

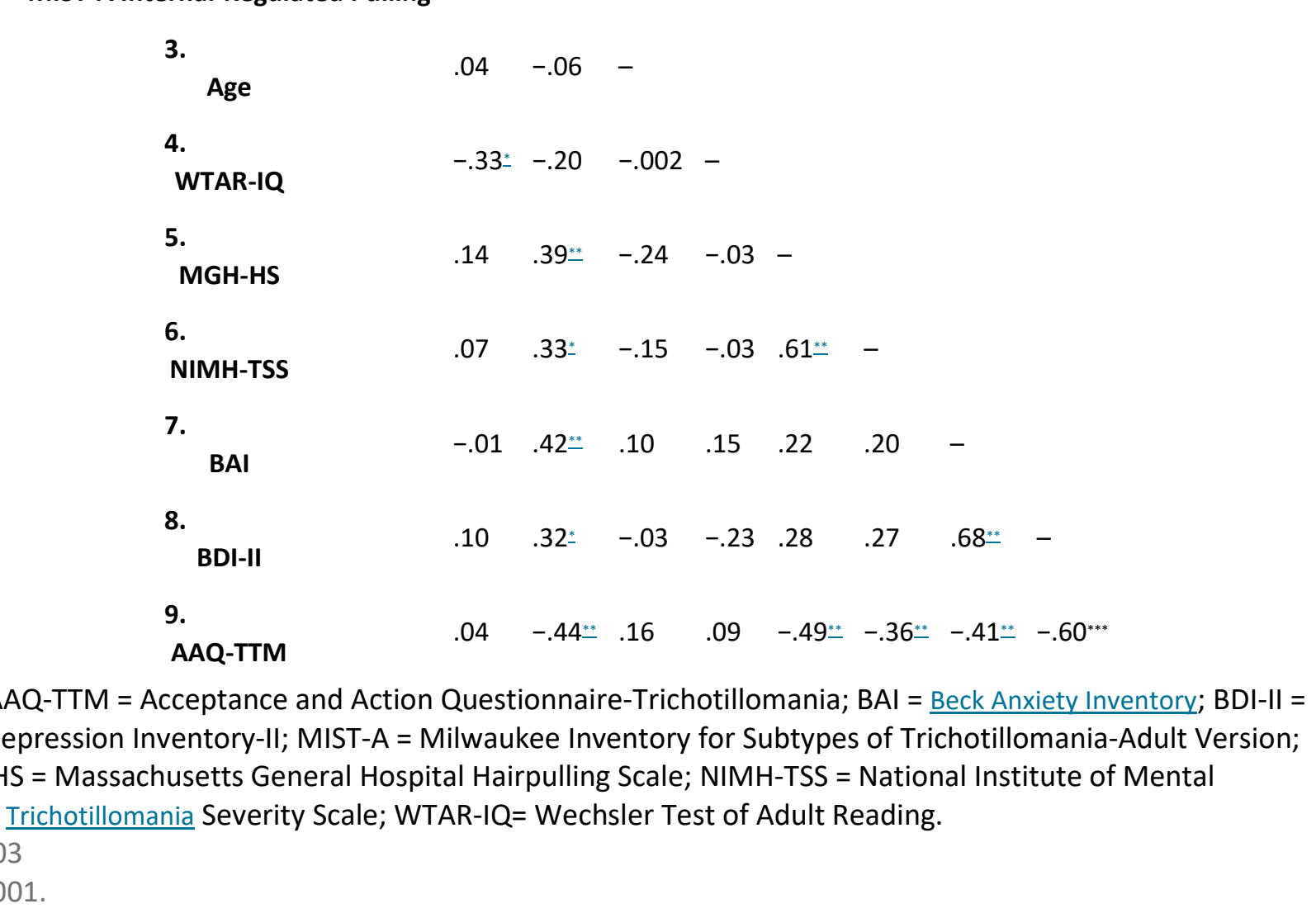

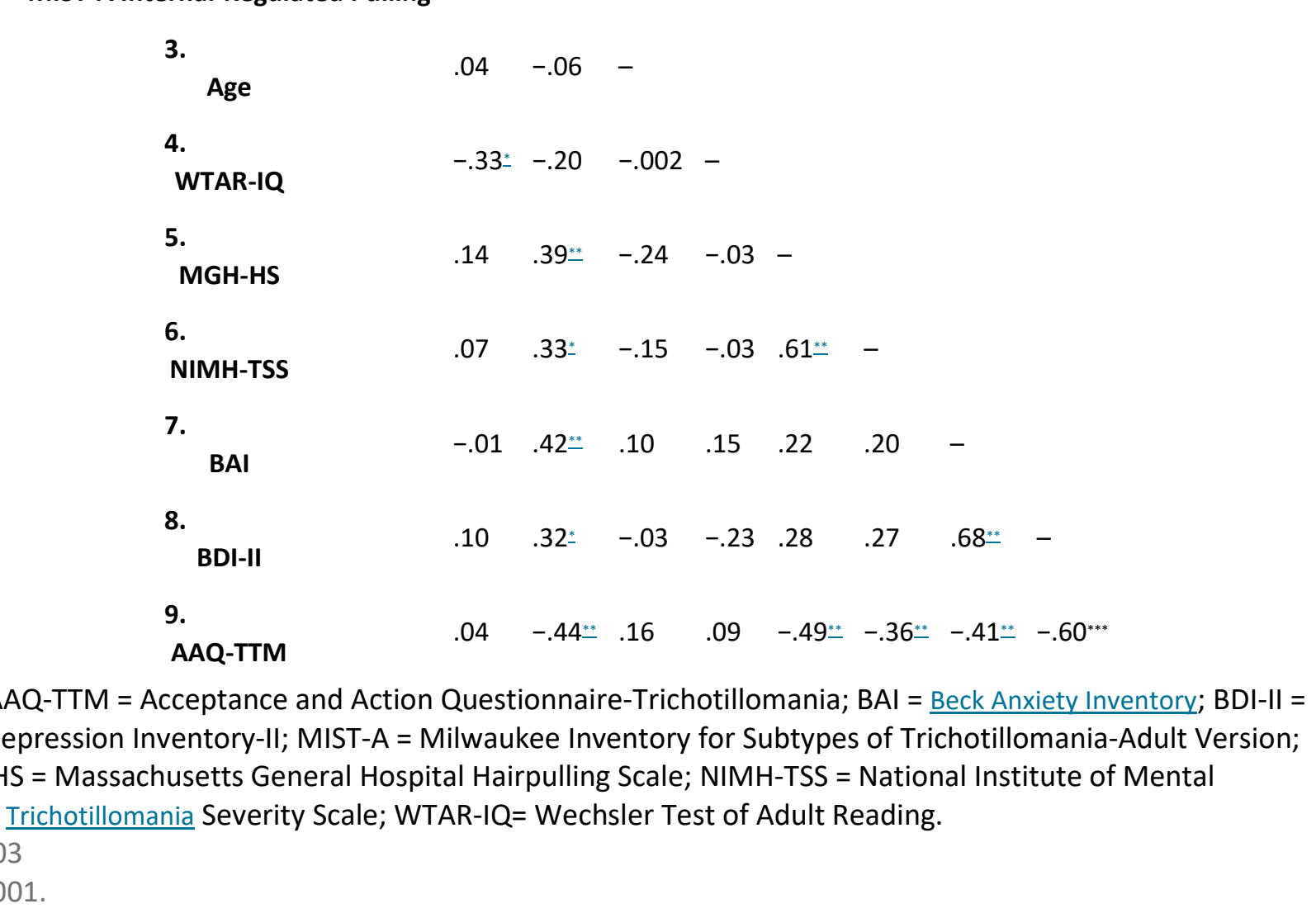

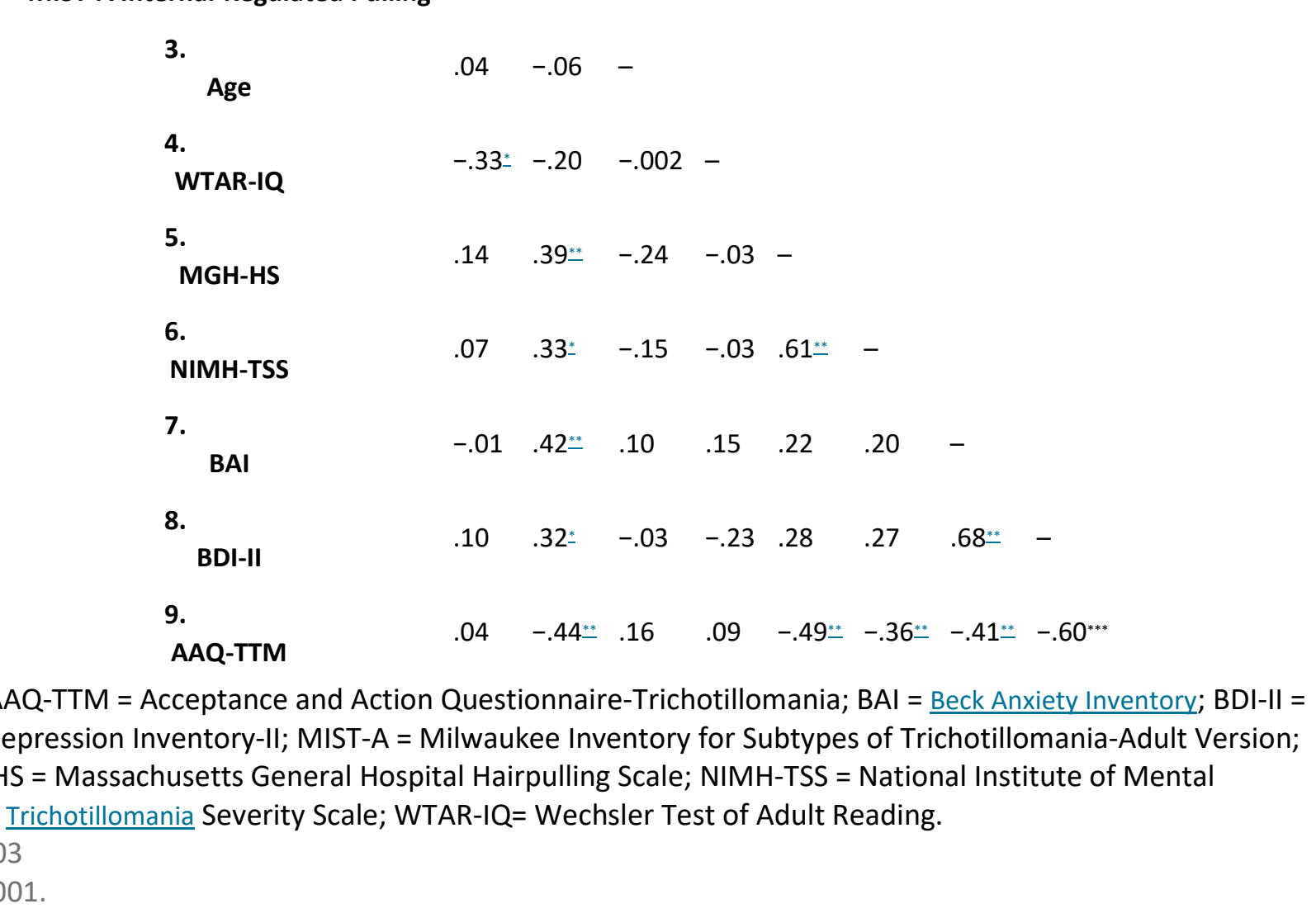

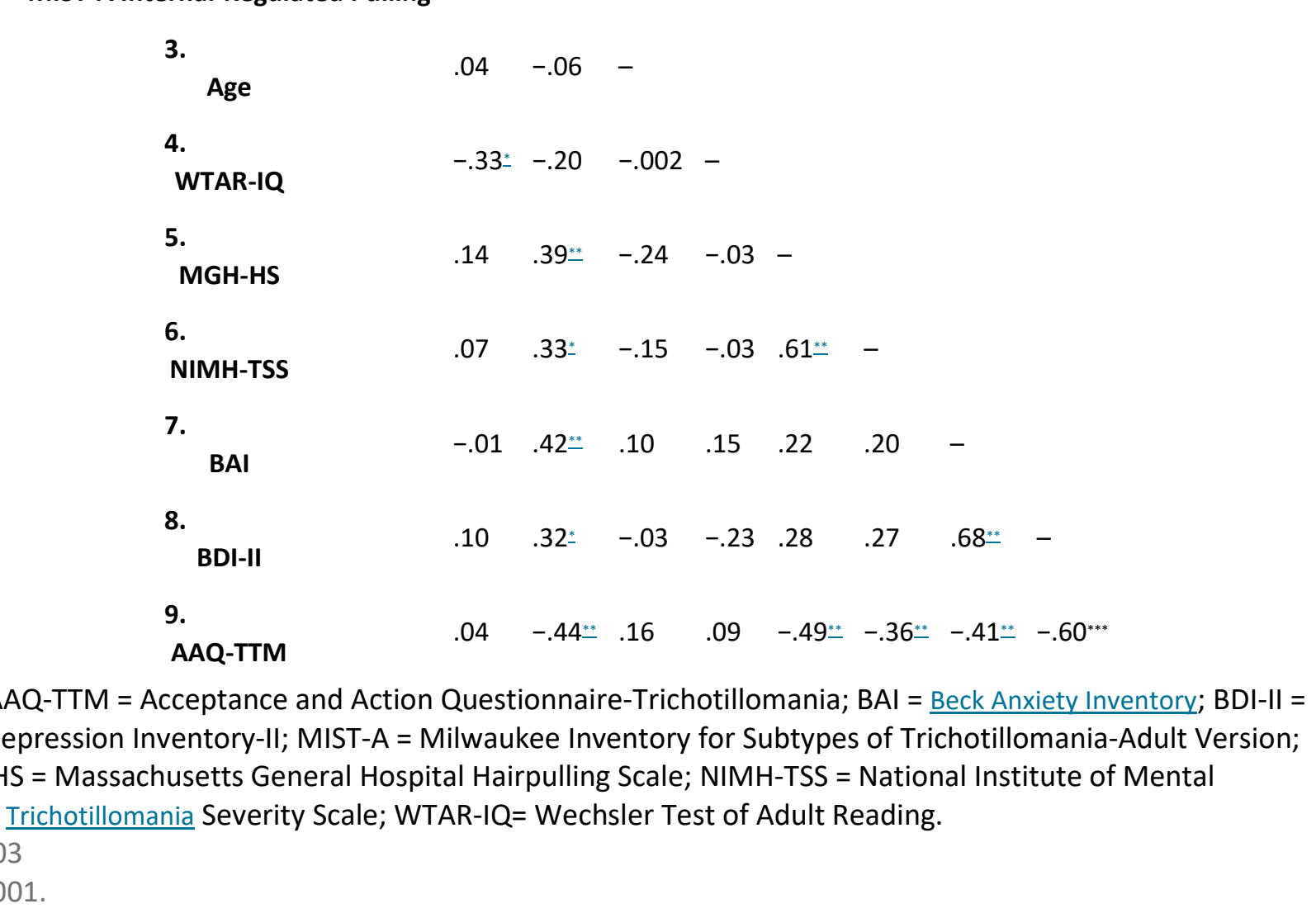

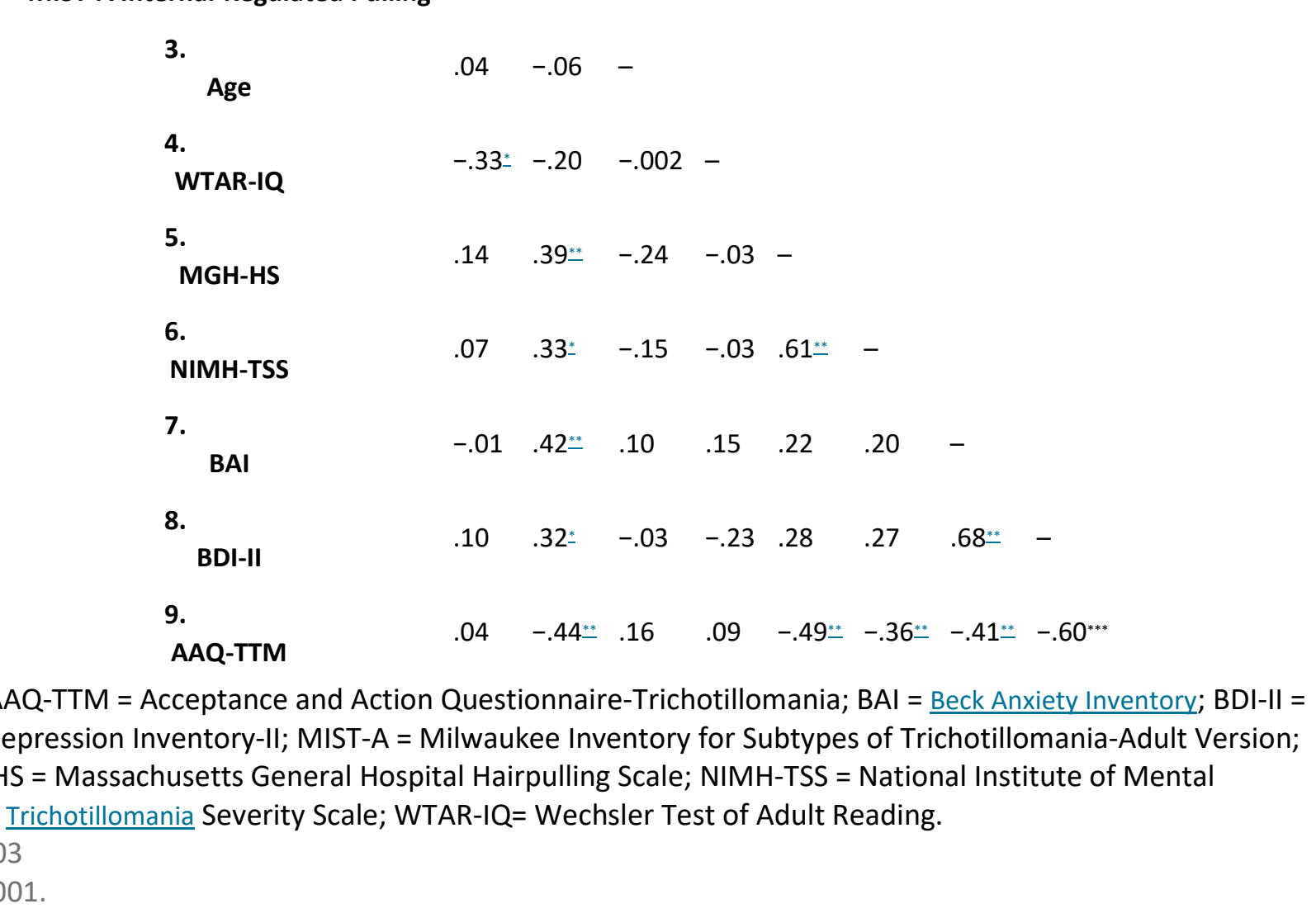

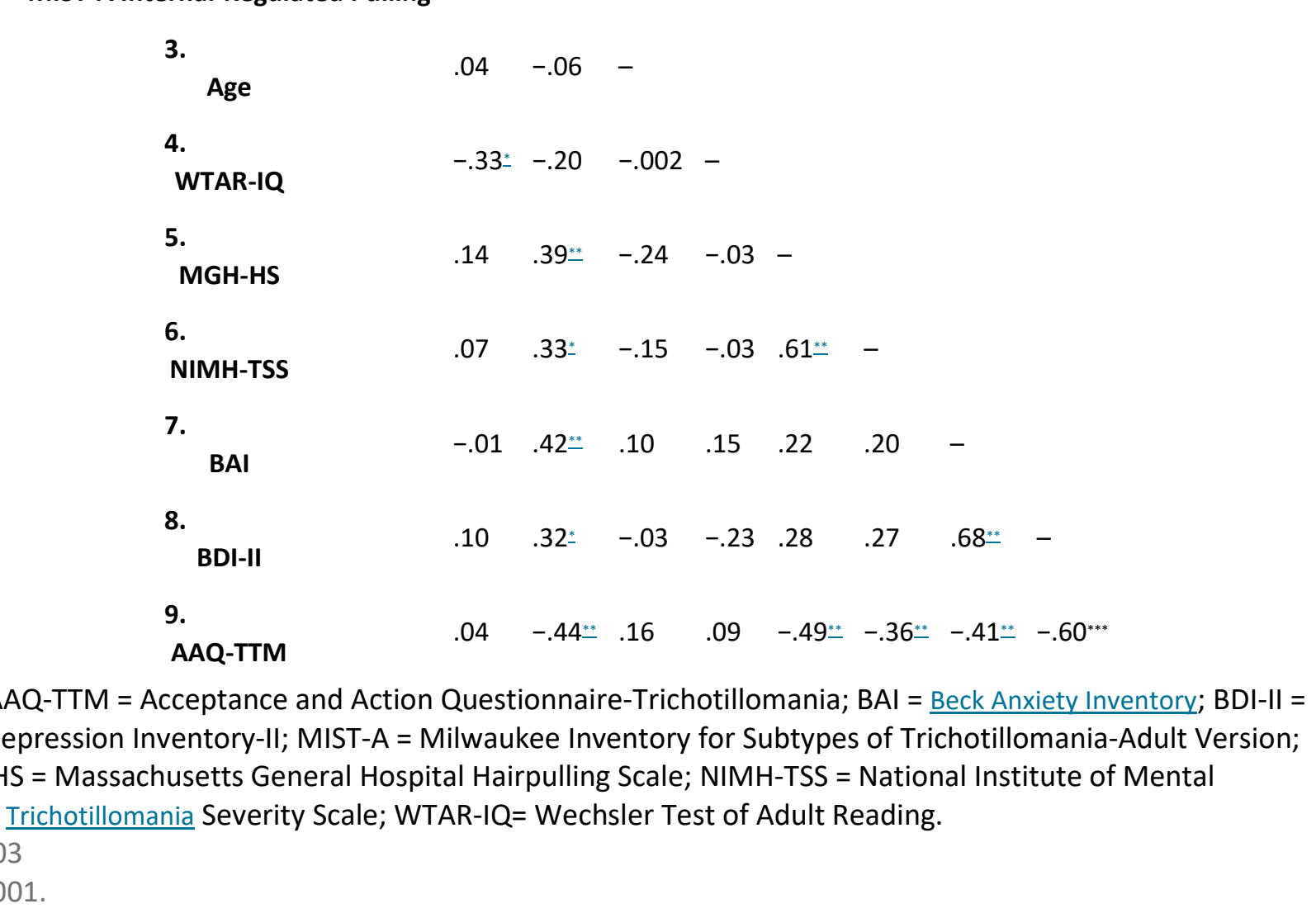

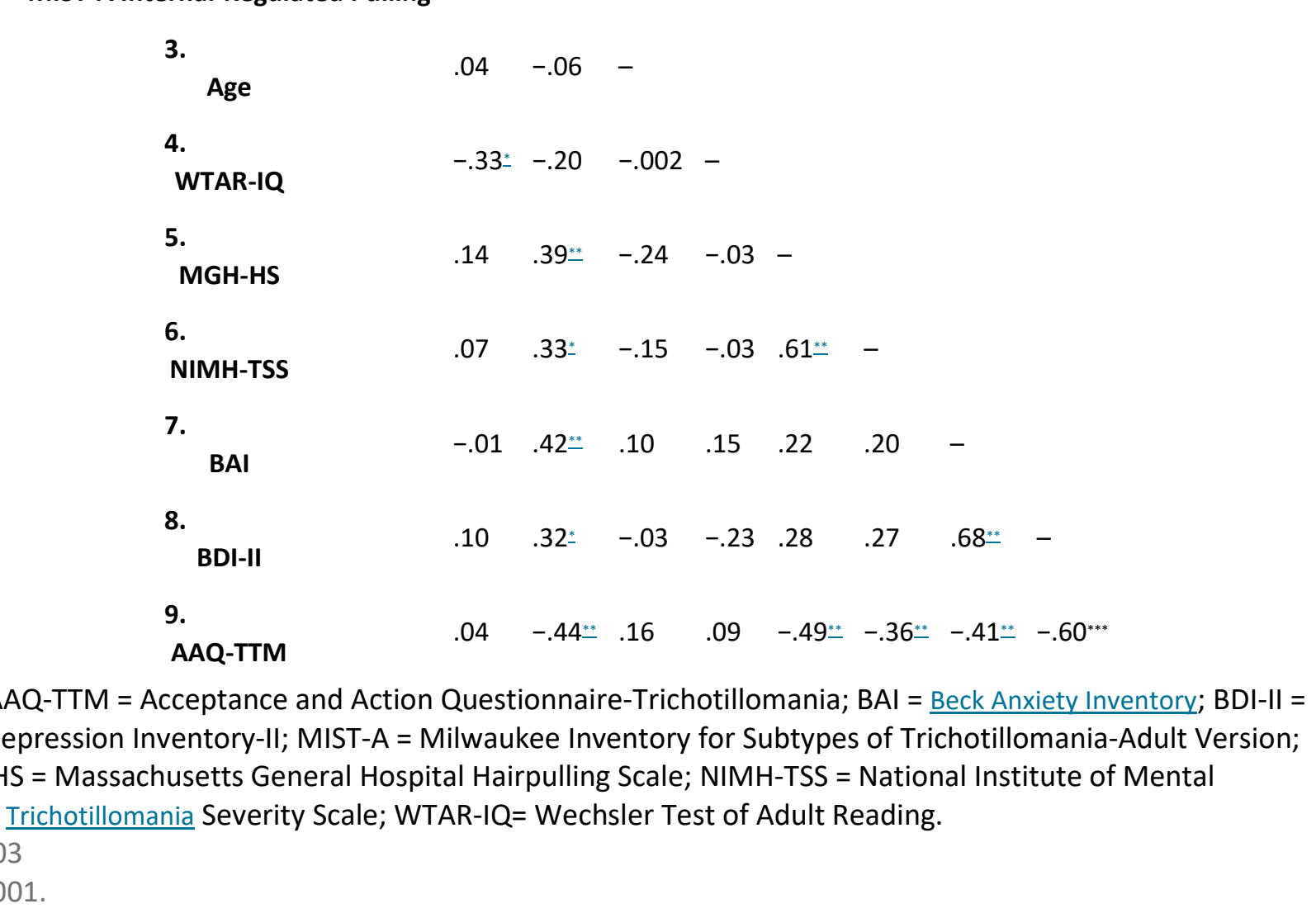

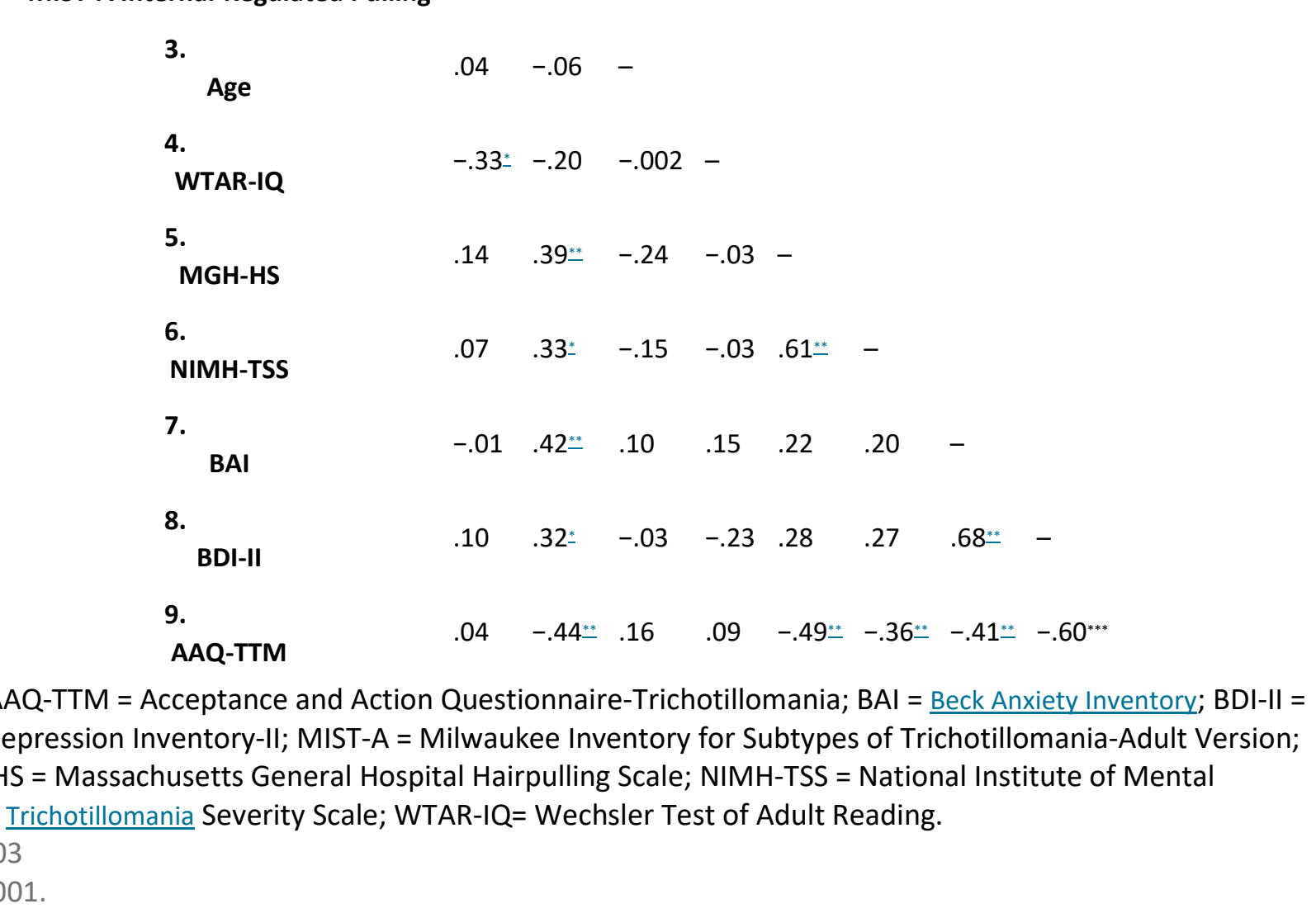

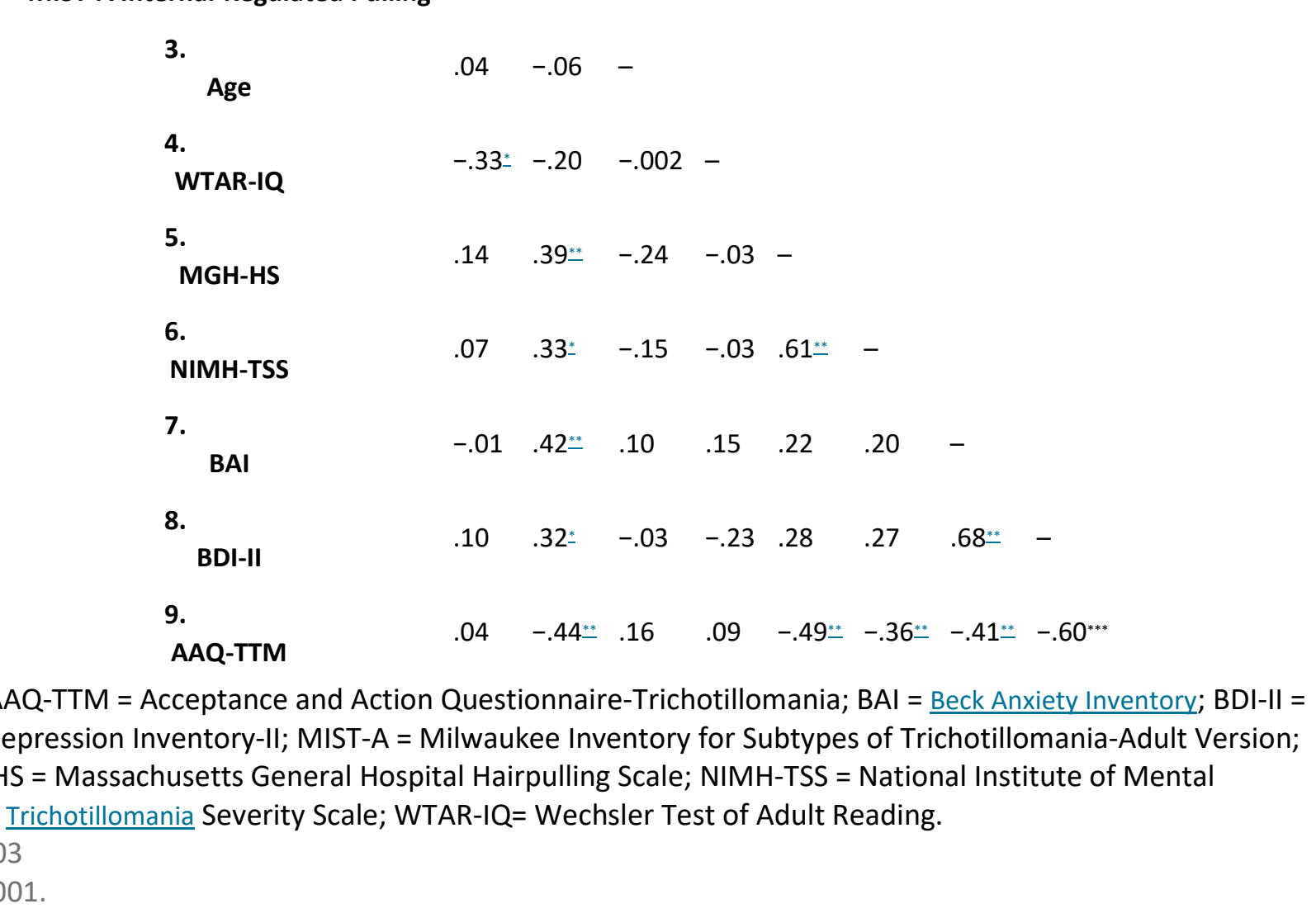

\section{1}

$\begin{array}{llllll}3 & 4 & 5 & 6 & 7 & 8\end{array}$

There were moderate positive correlations between scores on the "internal-regulated pulling" subscale and scores on the BAI $(p<.001)$ and the BDI-II $(p=.003)$, indicating that higher scores on the "internalregulating pulling" subscale were associated with higher levels of anxiety and depression. Moreover, there was a moderate negative correlation between scores on the "internal-regulated pulling" subscale and scores on the AAQ-TTM $(p<.001)$, indicating that higher scores on the "internal-regulating pulling" subscale were associated with a greater tendency to alter or control unpleasant internal experiences (i.e., greater experiential avoidance). Finally, there were moderate positive correlations between scores on the "internal-regulated pulling" subscale and scores on the MGH-HS $(p<.001)$ and NIMH-TSS $(p=.002)$, indicating that higher scores on the "internal-regulating pulling" subscale were associated with greater TTM severity. In contrast, scores on the "internal-regulated pulling" subscale were not significantly related to age $(p=.60)$ or scores on the WTAR-IQ $(p=.07)$.

There was a moderate negative correlation between scores on the "awareness of pulling" subscale and scores on the WTAR-IQ ( $p=.002)$, indicating that greater awareness of pulling was associated with greater verbal ability (low scores on the "awareness of pulling" subscale reflect greater awareness). In 
contrast, scores on the "awareness of pulling" subscale were not significantly associated with age $(p=.73)$, scores on the BAI $(p=.89)$, BDI-II $(p=.35)$, AAQ-TTM $(p=.70)$, MGH-HS $(p=.18)$, or NIMH-TSS $(p=.49)$.

To further explore the validity of the "awareness of pulling" subscale, scores on the "awareness of pulling" subscale were compared to a composite variable of awareness that was created for the current study. It was assumed that patients who were highly aware of their pulling would provide judgments of their pulling frequency that closely resembled judgments of their pulling frequency made by independent raters. Conversely, it was assumed that the discrepancy between patients' and independent evaluators' ratings of hair pulling frequency would be greater when patients' awareness of their pulling was low. Accordingly, the composite variable was created by comparing a self-report rating of pulling frequency (assessed by item 4 on the MGH-HS: "On an average day, how often do you actually pull your hair?") to an independent rating of pulling frequency (assessed by item 1 on the NIMH-TSS: "In the average day, for the past week, how much time did you spend pulling hairs?"). To create this composite variable, z-scores for item 4 on the MGH-HS (self-report of pulling frequency) and for item 1 on the NIMH-TSS (independent rating of participant's pulling frequency) were calculated. Z-scores for item 4 on the MGH-HS were then subtracted from z scores for item 1 on the $\mathrm{NIMH}$-TSS, and the absolute value of this difference was used as the composite variable of awareness. Correlational analysis showed that there was a small positive correlation between scores on the MISTA "awareness of pulling" subscale and the composite variable of awareness $\left(r_{s}=.25, p=.02\right)$, suggesting that less awareness was associated with greater discrepancy between participants' and independent raters' ratings of hair pulling frequency (higher scores on the "awareness of pulling" subscale reflect lower awareness). Notably, the composite variable of awareness was not correlated with the "internalregulated pulling" subscale $\left(r_{s}=.11, p=.29\right)$.

Results of these correlational analyses provide preliminary evidence for the validity of the "internalregulated pulling" and the "awareness of pulling" subscales of the MIST-A. In addition, these results further suggest the subscales measure different constructs.

\section{Discussion}

The current study reexamined the MIST-A's factor structure in a treatment-seeking sample. In contrast to the "automatic" and "focused" factors put forth by Flessner et al. (2008), the current study suggested a 13-item measure consisting of two subscales: a 5-item "awareness of pulling" subscale and an 8-item "internal-regulated pulling" subscale. The "awareness of pulling" subscale consisted of four items that were included on the original MIST-A "automatic" subscale and one item that was included 
on the original MIST-A "focused" subscale. All of the items on the "internal-regulated pulling" subscale were included on the original MIST-A "focused" subscale. The composition of the newly derived MISTA factor structure aligns with the notion that pulling may be more accurately described by its location on two dimensions (awareness of pulling and internal-regulating function of pulling), rather than by measuring the degree to which pulling corresponds to a "focused" and/or "automatic" style.

The current study's findings also provide preliminary evidence for the construct validity of the "internal-regulated pulling" and the "awareness of pulling" subscales. Consistent with findings that suggest the degree to which pulling serves to regulate internal experiences is positively associated with higher levels of negative affect (Diefenbach et al., 2002), correlational analyses indicated that "internal-regulated pulling" scores were positively associated with levels of anxiety and depression. In addition, consistent with the notion that hair pulling cued by internal states may be the behavioral manifestation of experiential avoidance (Begotka et al., 2004), "internal-regulated pulling" scores were associated with experiential avoidance. In contrast, measures of negative affect and experiential avoidance were not associated with scores on the "awareness of pulling" subscale.

Similarly, as hypothesized by Panza et al. (2013), the degree to which pulling is done with awareness was related with verbal ability (a proxy of IQ measured via the WTAR). Moreover, greater awareness of pulling was associated with reduced discrepancy between the participant's judgment of the frequency of their hair pulling and an interviewer's judgment of the frequency of the participant's hair pulling. Scores on the "internal-regulated pulling" subscale were not associated with either of these measures.

Correlational analysis also indicated that the "internal-regulating pulling" subscale was positively associated with overall disorder severity, but the "awareness of pulling" subscale was not. Reasons for this are unclear, but given that both the MGH-HS and the NIMH-TSS include several questions regarding sensory stimuli in relation to pulling (e.g., item 3 on the MGH-HS "On an average day, how much control do you have over the urges to pull your hair? " and item 4 on the NIMH-TSS "Did you attempt to resist the urge to pull? ") (Keuthen et al., 1995; Swedo et al., 1989), these TTM severity measures may be more indicative of internal-regulating pulling than TTM severity, per se. Accordingly, the lack of a relationship found between the "awareness of pulling" subscale and the MGH-HS and NIMH-TSS may not necessarily indicate that no relationship exists between awareness of pulling and disorder severity.

While the "awareness of pulling" subscale and the "internal-regulated pulling" subscale found in the current study are similar to the "Intention" and "Emotion" subscales observed by Keuthen et al. $\underline{(2015)}$ in their reanalysis of the MIST-A, there are differences. First, the "Intention" subscale suggested 
by Keuthen et al. (2015), which is comparable to the "awareness of pulling" subscale, includes cognition-related items (e.g., "I intentionally start to pull my hair" and "I have thoughts about wanting to pull my hair before ( actually pull"). However, these cognition-related items were included on the "internal-regulated pulling" subscale not the "awareness of pulling" subscale in the current analysis. Moreover, the "Emotion" subscale suggested by Keuthen et al. (2015), which is comparable to the "internal-regulated pulling" subscale, solely consisted of emotion-related items. In contrast, the "internal-regulated pulling" subscale presented here included items related to a variety of internal experiences (e.g., "I have a strange sensation just before I pull my hair" and "I have thoughts about wanting to pull my hair before I actually pull"). Overall, the current study appears to be more consistent with research that suggests hair pulling varies in terms of awareness (Christenson, Mackenzie, \& Mitchell, 1991; du Toit et al., 2001; Lochner et al., 2010) and function (Diefenbach et al., 2002; Mansueto, Stemberger, Thomas, \& Golomb, 1997). Moreover, the current study appears to be more consistent with research that suggests hair pulling awareness and function are independent of each other (Duke, Keeley, Geffken et al., 2010; Duke, Keeley, \& Ricketts, 2010; Shusterman et al., $\underline{2009)}$.

The current study may have important implications for treatment for TTM. Indeed, determining the degree to which clients' pulling is done with awareness and done to regulate internal states may help clinicians determine what type of treatment would be best for their client. For example, Habit Reversal Training (HRT) may be most useful for individuals who pull their hair without awareness (Franklin et al., 2012) and whose pulling is not closely tied to internal states. In contrast, TTM treatments that include affective regulation components, such as behavior therapy enhanced with Acceptance and Commitment Therapy (Woods \& Twohig, 2008) and with Dialectical Behavior Therapy (Keuthen et al., 2010), may be useful for individuals who pull their hair in relation to their internal states (Franklin et al., 2012). Compared to traditional behavior therapy (e.g., HRT), meta-analytic investigations suggest that enhanced behavior therapies tend to lead to more robust TTM severity reductions (McGuire et al., 2014). However, research has not examined whether individuals with higher levels of internal regulated pulling demonstrate greater TTM severity reductions after undergoing enhanced behavior therapy compared to individuals with lower levels of internal regulated pulling. Future research should examine whether individuals with different treatment styles respond best to different treatments.

In addition, the current study may have important implications for TTM conceptualization. Although the two factors identified in the current analysis align with findings from past research, we suspect that these factors alone do not encompass all existing TTM pulling styles or subtypes. Along with awareness of pulling and the capacity of pulling to regulate internal experiences, it has been noted that hair pulling can serve a variety of purposes. For instance, the comprehensive behavioral model of TTM 
posits that clinical hair pulling can function to control or alter external experiences (e.g., settings and activities) as well as internal experiences (e.g., emotions, cognitions, sensory stimuli; Mansueto et al., 1997; Woods et al., 2006). It has also been posited that some hair pulling may be non-functional or simply a product of motor abnormalities (Begotka et al., 2004; Bohne, Savage, Deckersbach, Keuthen, \& Wilhelm, 2008; Stein et al., 2010). Consequently, the factors identified in the current study likely do not capture all of the ways in which hair pulling generally varies. Accordingly, future research should continue to consider other factors that may be important to TTM phenomenology.

Moreover, we suspect that the factors identified in the current paper also warrant a more thorough examination, as they are relatively broad and consist of a high degree of variability. For example, there are several types of internal experiences that trigger hair pulling (Christenson, Ristvedt, \& Mackenzie, 1993; du Toit et al., 2001; Penzel, 2003; Roberts, O’Connor, \& Bélanger, 2013). In addition, the effect that hair pulling has on the internal experiences that trigger hair pulling also appears to vary: while some hair pulling appears to decrease certain internal states (e.g., negative affect), some hair pulling appears to increase internal states (e.g., positive affect; Diefenbach et al., 2002; du Toit et al., 2001; Grant, Odlaug, \& Potenza, 2007; Penzel, 2003; Roberts et al., 2013). Accordingly, future research should investigate whether factors that assess these points of variation would be more clinically meaningful than the broad factors identified in the current analysis. Future research should also explore relationships between current or yet-to-be-discovered pulling factors and other potential TTM subtypes (e.g., subtypes related to age of onset).

While the current study provides evidence for the validity of an "awareness of pulling" and an "internal regulating pulling" subscale, the current study did have limitations. First, the sample size was relatively small for factor analysis. However, the study's subject to item ratio was greater than the 5:1 rule of thumb recommended for factor analysis (Cattell, 1978; Gorsuch, 1974; Stevens, 1996), and KMO indicated that the sample was suitable for factor analysis. In addition, it should be noted that the study's sample is among the largest sample of individuals seeking treatment for TTM ever collected (Bloch et al., 2007). This is particularly notable as the study's sample was well-characterized and consisted entirely of individuals seeking treatment specifically for TTM. Second, the sample largely consisted of females, which may limit generality of the findings. However, this appears to be consistent with the TTM population (Duke, Keeley, Geffken et al., 2010). Third, the sample consisted of individuals who met DSM-IV-TR defined TTM, which requires the experience of tension prior to pulling and relief after pulling (APA, 2000). The DSM-5 has subsequently dropped these criteria (APA, 2013). Fourth, although the percent of variance explained by the current analysis is greater than that reported by Flessner et al. (2008), it is still relatively low. This may speak to limited ability of the MIST-A's item content to capture the breadth and depth of TTM's phenomenological complexity and highlights the 
need to further examine pulling styles within TTM. As noted previously, there are several factors that are relevant to TTM that were not considered in the current analysis (e.g., sensory processing). Future research should consider these variables when attempting to identify subtypes of TTM.

\section{Conclusions}

The MIST-A is the only psychometrically validated measure of pulling styles for TTM adult populations, but results of the current study suggest that its original factor structure may not be maximally effective in describing pulling styles in TTM. Rather than supporting a "focused" versus "automatic" approach, results of the current analysis suggest that pulling styles can be better described by the degree to which pulling is done with awareness and the extent to which pulling functions to regulate internal experiences. Given that hair pulling likely serves a variety of functions, however, the two proposed factors may be incomplete. Accordingly, the current analysis is not intended to present a comprehensive modification of the MIST-A, but to challenge present conceptualization of pulling styles. Rather, confirmatory factor analysis (CFA) of the MIST-A in a larger sample is necessary before conclusions about the optimal MIST-A factor structure can be made. In addition to examining the MISTA factor structure, future research should continue to examine TTM phenomenological subtypes and explore dimensional models of pulling style within TTM, as such research may greatly contribute to advances in TTM treatment.

\section{References}

American Psychiatric Association, 2000. American Psychiatric Association. Diagnostic and Statistical Manual of Mental

Disorders. (text rev). (4th ed.), American Psychiatric Association, Arlington (2000)

American Psychiatric Association, 2013. American Psychiatric Association. Diagnostic and Statistical Manual of Mental

Disorders (5th ed.), American Psychiatric Association, Arlington (2013)

Beck and Steer, 1990. A. Beck, R. Steer. Manual for the Beck Anxiety Inventory, The Psychological Corporation, San Antonio(1990)

Beck et al., 1988. A.T. Beck, N. Epstein, G. Brown, R.A. Steer. An inventory for measuring clinical anxiety: Psychometric properties. Journal of Consulting and Clinical Psychology, 56 (6) (1988), pp. 893-897, 10.1037/0022-006X.56.6.893

Beck et al., 1996. A.T. Beck, R.A. Steer, G.K. Brown. Manual for the Beck Depression Inventory-II, The Psychological Corporation,, San Antonio (1996)

Begotka et al., 2004. A.M. Begotka, D.W. Woods, C.T. Wetterneck. The relationship between experiential avoidance and the severity of trichotillomania in a nonreferred sample. Journal of Behavior Therapy and Experimental Psychiatry, 35 (1) (2004), pp. 17-24, 10.1016/j.jbtep.2004.02.001

Bloch et al., 2007. M.H. Bloch, A. Landeros-Weisenberger, P. Dombrowski, B. Kelmendi, R.Wegner, J. Nudel, ..., V. Coric.

Systematic review: Pharmacological and behavioral treatment for trichotillomania. Biological

Psychiatry, 62 (2007), pp. 839-846, 10.1016/j.biopsych.2007.05.019 
Bohne et al., 2008. A. Bohne, C.R. Savage, T. Deckersbach, N.J. Keuthen, S. Wilhelm. Motor inhibition in trichotillomania and obsessive-compulsive disorder. Journal of Psychiatric Research, 42 (2) (2008), pp. 141-

150, 10.1016/j.jpsychires.2006.11.008

Cattell, 1978. R.B. Cattell. The scientific use of factor analysis in behavioral and life sciences, Plenum, New York(1978), 10.1007/978-1-4684-2262-7

Cattell and Vogelmann, 1977. R.B. Cattell, S. Vogelmann. A comprehensive trial of the scree and KG criteria for determining the number of factors. Multivariate Behavioral Research, 12 (3) (1977), pp. 289-

$325,10.1207 / \mathrm{s} 15327906 \mathrm{mbr} 12032$

Christenson et al., 1991. G.A. Christenson, T.B. Mackenzie, J.E. Mitchell. Characteristics of 60 adult chronic hair pullers. The American Journal of Psychiatry, 148 (3) (1991), pp. 365-370, 10.1176/ajp.148.3.365

Christenson et al., 1993. G.A. Christenson, S.L. Ristvedt, T.B. Mackenzie. Identification of trichotillomania cue profiles. Behaviour Research and Therapy, 31 (3) (1993), pp. 315-320, 10.1016/0005-7967(93)90030-X

Cortina, 1993. J.M. Cortina. What is coefficient alpha? An examination of theory and applications. Journal of Applied Psychology, 78 (1) (1993), pp. 98-104, 10.1037/0021-9010.78.1.98

Diefenbach et al., 2002. G.J. Diefenbach, S. Mouton-Odum, M.A. Stanley. Affective correlates of trichotillomania. Behaviour Research and Therapy, 40 (11) (2002), pp. 1305-1315, 10.1016/S0005-7967(02)00006-2

Diefenbach et al., 2005. G.J. Diefenbach, D.F. Tolin, J. Crocetto, N. Maltby, S. Hannan. Assessment of trichotillomania: A psychometric evaluation of hair-pulling scales Journal of Psychopathology and Behavioral Assessment, 27 (3) (2005), pp. 169-178, 10.1007/s10862-005-0633-7

du Toit et al., 2001. P.L. du Toit, J. van Kradenburg, D.J. Niehaus, D.J. Stein. Characteristics and phenomenology of hairpulling: An exploration of subtypes. Comprehensive Psychiatry, 42 (3) (2001), pp. $247-$

256, 10.1053/comp.2001.23134

Duke et al., 2010. D.C. Duke, M.L. Keeley, G.R. Geffken, E.A. Storch. Trichotillomania: A current review. Clinical Psychology Review, 30 (2) (2010), pp. 181-193, 10.1016/j.cpr.2009.10.008

Duke et al., 2010. D.C. Duke, M.L. Keeley, E.J. Ricketts, G.R. Geffken, E.A. Storch. The phenomenology of hairpulling in college students. Journal of Psychopathology and Behavioral Assessment, 32 (2) (2010), pp. 281 $292,10.1007 / \mathrm{s} 10862-009-9150-4$

Flessner et al., 2008. C.A. Flessner, D.W. Woods, M.E. Franklin, S.E. Cashin, N.J. Keuthen, Trichotillomania Learning CenterScientific Advisory Board (TLC-SAB)The Milwaukee Inventory for Subtypes of Trichotillomania-Adult Version (MIST-A): Development of an instrument for the assessment of "focused" and "automatic" hair pulling. Journal of Psychopathology and Behavioral Assessment, 30 (1) (2008), pp. 20-30, 10.1007/s10862-007-9073-x

Franklin et al., 2012. M.E. Franklin, K. Zagrabbe, K.L. Benavides. Trichotillomania and its treatment: A review and recommendations. Expert Review of Neurotherapeutics, 11 (8) (2012), pp. 1165-1174, 10.1586/ern.11.93

Fydrich et al., 1992. T. Fydrich, D. Dowdall, D.L. Chambless. Reliability and validity of the Beck Anxiety Inventory. Journal of Anxiety Disorders, 6 (1) (1992), pp. 55-61, 10.1016/0887-6185(92)90026-4

Gorsuch, 1974. R. Gorsuch. Factor Analysis, W.B. Saunders Company, Philadelphia (1974)

Grant et al., 2007. J.E. Grant, B.L. Odlaug, M.N. Potenza. Addicted to hair pulling? How an alternate model of trichotillomania may improve treatment outcome. Harvard Review of Psychiatry, 15 (2) (2007), pp. 80$85, \underline{10.1080 / 10673220701298407}$ 
Hair et al., 1995. J. Hair, B. Black, R. Anderson, R. Tatham. Multivariate data analysis: Text and readings. Prentice Hall, Englewoods Cliffs, NJ (1995)

Harrison and Franklin, 2012. J.P. Harrison, M.E. Franklin. Pediatric trichotillomania. Current Psychiatry Reports, 14 (3) (2012), pp. 188-196, 10.1007/s11920-012-0269-8

Henson and Roberts, 2006. R.K. Henson, J.K. Roberts. Use of exploratory factor analysis in published research: Common errors and some comment on improved practice. Educational and Psychological Measurement, 66 (2006), pp. 393-416, 10.1177/0013164405282485

Houghton et al., 2014. D.C. Houghton, S.N. Compton, M.P. Twohig, S.M. Saunders, M.E.Franklin, A.M. NealBarnett, ..., D.W. Woods. Measuring the role of psychological inflexibility in trichotillomania. Psychiatry Research, 220 (1-2) (2014), pp. 356-361, 10.1016/j.psychres.2014.08.003

Kaiser, 1974. H.F. Kaiser. An index of factorial simplicity. Psychometrika, 39 (1) (1974), pp. 31-36, 10.1007/BF02291575 Keuthen et al., 2005. N.J. Keuthen, A. Bohne, M. Himle, D.W. Woods. Advances in the conceptualization and treatment of body-focused repetitive behaviors. B. Ling (Ed.), Obsessive compulsive disorder research, Nova Science Publishers, Inc, New York (2005), pp. 1-29

Keuthen et al., 2007. N.J. Keuthen, C.A. Flessner, D.W. Woods, M.E. Franklin, D.J. Stein, S.E.Cashin. Factor analysis of the Massachusetts General Hospital Hairpulling Scale. Journal of Psychosomatic Research, 62 (6) (2007), pp. 707709, 10.1016/j.jpsychores.2006.12.003

Keuthen et al., 1995. N.J. Keuthen, R.L. O'Sullivan, J.N. Ricciardi, D. Shera, C.R. Savage, A.S.Borgmann, ..., L. Baer. The Massachusetts General Hospital (MGH) Hairpulling Scale: 1. Development and factor analyses. Psychotherapy and Psychosomatics, 64 (3-4) (1995), pp. 141-145, 10.1159/000289003

Keuthen et al., 2010. N.J. Keuthen, B.O. Rothbaum, S.S. Welch, C. Taylor, M. Falkenstein, M.Heekin, ..., M.A. Jenike. Pilot trial of dialectical behavior therapy-enhanced habit reversal for trichotillomania. Depression and Anxiety, 27 (10) (2010), pp. 953-959, 10.1002/da.20732

Keuthen et al., 2015. N. Keuthen, E. Tung, D. Woods, M. Franklin, E. Altenburger, D. Pauls, C.Flessner. Replication study of the Milwaukee inventory for subtypes of trichotillomania-adult version in a clinically characterized sample. Behavior Modification, 39 (4) (2015), pp. 580-599, 10.1177/0145445515580533

Kline, 2000. R.B. Kline. Handbook of psychological testing (2nd ed.), Routledge, Abingdon (2000)

Lochner et al., 2010. C. Lochner, S. Seedat, D. Stein. Chronic hair-pulling: Phenomenology-based subtypes. Journal of Anxiety Disorders, 24 (2010), pp. 196-202, 10.1016/j.janxdis.2009.10.008

Mansueto et al., 1997. C. Mansueto, R.M.T. Stemberger, A.M. Thomas, R.G. Golomb. Trichotillomania: A comprehensive behavioral model. Clinical Psychology Review, 17 (5) (1997), pp. 567-577, 10.1016/S0272-7358(97)00028-7

McGuire et al., 2014. J.F. McGuire, D. Ung, R.R. Selles, O. Rahman, A.B. Lewin, T.K. Murphy, E.A. Storch. Treating trichotillomania: A meta-analysis of treatment effects and moderators for behavior therapy and serotonin reuptake inhibitors. Journal of Psychiatric Research, 58 (2014), pp. 76-83, 10.1016/j.jpsychires.2014.07.015

Norberg et al., 2007. M.M. Norberg, C.T. Wetterneck, D.W. Woods, C.A. Conelea. Experiential avoidance as a mediator of relationships between cognitions and hair-pulling severity. Behavior Modification, 31 (2007), pp. 367381, 10.1177/0145445506297343 
O’Sullivan et al., 1995. R.L. O’Sullivan, N.J. Keuthen, C.F. Hayday, J.N. Ricciardi, M.L. Buttolph, M.A. Jenike, L. Baer. The Massachusetts General Hospital (MGH) Hairpulling Scale: 2. Reliability and validity. Psychotherapy and Psychosomatics, 64 (3-4) (1995), pp. 146-148, 10.1159/000289004.

Panza et al., 2013. K.E. Panza, C. Pittenger, M.H. Bloch. Age and gender correlates of pulling in pediatric trichotillomania. Journal of the American Academy of Child and Adolescent Psychiatry, 52 (3) (2013), pp. 241-

249, 10.1016/j.jaac.2012.12.019

Penzel, 2003. F. Penzel. The hair-pulling problem: A complete guide to trichotillomania, Oxford University Press, New York (2003)

Roberts et al., 2013. S. Roberts, K. O’Connor, C. Bélanger. Emotion regulation and other psychological models for bodyfocused repetitive behaviors. Clinical Psychology Review, 33 (6) (2013), pp. 745-762, 10.1016/j.cpr.2013.05.004. Shusterman et al., 2009. A. Shusterman, L. Feld, L. Baer, N. Keuthen. Affective regulation in trichotillomania: Evidence from a large-scale internet survey. Behaviour Research and Therapy, 47 (8) (2009), pp. 637 -

644, 10.1016/j.brat.2009.04.004

Sprinkle et al., 2002. S.D. Sprinkle, D. Lurie, S.L. Insko, G. Atkinson, G.L. Jones, A.R. Logan, N.N. Bissada. Criterion validity, severity cut scores, and test-retest reliability of the Beck Depression Inventory-II in a university counseling center sample. Journal of Counseling Psychology, 49 (3) (2002), pp. 381-385, 10.1037/0022-0167.49.3.381

Stanley et al., 1999. M.A. Stanley, J.K. Breckenridge, A.G. Snyder, D.M. Novy. Clinician-rated measures of hair pulling: A preliminary psychometric evaluation. Journal of Psychopathology and Behavioral Assessment, 21 (2) (1999), pp. 157-170, 10.1023/A:1022160522908

Stein et al., 2010. D.J. Stein, J.E. Grant, M.E. Franklin, N. Keuthen, C. Lochner, H.S. Singer, D.W. Woods. Trichotillomania (hair pulling disorder), skin picking disorder, and stereotypic movement disorder: Toward DSM-V. Depression and Anxiety, 27 (6) (2010), pp. 611-626, 10.1002/da.20700

Stevens, 1996. J. Stevens. Applied multivariate statistics for the social sciences (3rd ed.), Lawrence Erlbaum, Mahwah (1996) Strauss et al., 2006. E.H. Strauss, E.M.S. Sherman, O. Spreen. A compendium of neuropsychological tests: administration norms and commentary (3rd ed.), Oxford University Press, New York (2006)

Swedo et al., 1989. S.E. Swedo, J.L. Rapoport, H. Leonard, M. Lenane, D. Cheslow. Obsessive-compulsive disorder in children and adolescents. Archives of General Psychiatry, 46 (4) (1989), pp. 335-

341, 10.1001/archpsyc.1989.01810040041007

Tabachnick and Fidell, 2007. B.G. Tabachnick, L.S. Fidell. Using multivariate statistics. (5th ed.), Pearson Education Incorporated, Boston (2007)

The Psychological Corporation, 2001. The Psychological Corporation. WTAR: Wechsler Test of Adult Reading. (4th ed.), Harcourt Assessment, San Antonio (2001)

Woods et al., 2006. D.W. Woods, C.A. Flessner, M.E. Franklin, C.T. Wetterneck, M.R. Walther, E.R. Anderson, D. Cardona. Understanding and treating trichotillomania: What we know and what we don't know. The Psychiatric Clinics of North America, 29 (2) (2006), pp. 487-501, 10.1016/i.psc.2006.02.009

Woods and Twohig, 2008. D.W. Woods, M.P. Twohig. Trichotillomania: An ACT-enhanced behavior therapy approach therapist guide, Oxford University Press, New York (2008) 
